\title{
Eczacılık Fakültesi Öğrencilerinin Obeziteye Yönelik Farkındalıkları ${ }^{*}$
}

\author{
Awareness of Pharmacy Faculty Students Towards Obesity \\ Miray Arslani, Tuğse Akkayaii, Sevgi Şariii
}

'Dr. Öğr. Üyesi, Van Yüzüncü Yıl Üniversitesi Eczacılık Fakültesi Eczacılık İşletmeciliği A.D., https://orcid.org/0000-0003-2786-4610

ii Yardımcı Eczacı. Fazilet Eczanesi, Ankara, https://orcid.org/0000-0001-6281-2563

iii Prof. Dr., Ankara Üniversitesi Eczacılık Fakültesi Eczacılık İşletmeciliği A.D., https://orcid.org/0000-0002-2816-9575

öz

Amaç: Bu çalışmanın temel amacı eczacılık fakültesi öğrencilerinin obeziteye yönelik farkındalıklarının belirlenmesidir.

Yöntem: Bu çalışma kapsamında Ankara Üniversitesi Eczacılık Fakültesi 1. ve 4. sınıfında okumakta olan öğrencilere bir anket uygulaması yapılmıştır. Uygulanan anket, Allen (2011) tarafından geliştirilmiş ve Kafkas ve Özen (2014) tarafından Türkçe geçerlilik ve güvenilirliği yapılmış olan “Obezite Farkındalık Ölçeği”ni içermektedir. Ölçekte yer alan ifadeler (1) Kesinlikle katılmıyorum - (4) Kesinlikle katılıyorum olacak şekilde 4'lü Likert tipi derecelendirilmeyle puanlanmıştır. Anket formundan elde edilen veriler IBM SPSS 22.0 paket programının yardımıyla öncelikle betimleyici istatistiksel analizlere tabi tutulmuş, ardından LISREL 8.80 programı aracılı̆̆ ile doğrulayıcı faktör analizi uygulanmıştır.

Bulgular: Çalışmaya 203 öğrenci katılım sağlamıştır. Doğrulayıcı faktör analizi sonucuna fiziksel aktivite, beslenme ve obezite farkındalık faktörlerinden oluşan üç faktörlü yapı doğrulanmış olup, ölçeğe ait uyum indekslerinin değerlendirilmesiyle bu ölçeğin eczacılık fakültesi öğrencileri için de geçerli ve güvenilir bir ölçek olduğu belirlenmiştir.

Sonuç: Çalışmada elde edilen bulgular, geleceğin eczacısı olan eczacılık fakültesi öğrencilerinin obeziteye yönelik farkındalık düzeylerinin arttırımasında eğitimin etkin olduğunu ortaya koymuştur. Bu bağlamda eczacılık fakültelerinde sağlıklı yaşam, obezite ve kilo yönetimi gibi konulara daha çok yer verilmesinin öğrencilerin gelecekteki uygulamalarına ışık turacağı düşünülmektedir.

Anahtar kelimeler: Doğrulayıc faktör analizi, Eczacılık, Obezite

ABSTRACT

Objective: The primary purpose of this study is to determine the awareness of the students of pharmacy faculty towards obesity.

Method: Within the scope of this study, a questionnaire was applied to students studying at Ankara University Faculty of Pharmacy 1st and 4th grade. The applied questionnaire includes the "Obesity Awareness Scale", developed by Allen (2011), also validity and reliability in Turkish were made by Kafkas and Özen (2014). Statements in the scale are rated as (1) Strongly disagree - (4) Strongly agree with 4-points Likert type rating. The data obtained from the questionnaire was firstly subjected to descriptive statistical analysis with the help of the IBM SPSS 22.0 package program. Then confirmatory factor analysis was applied via the LISREL 8.80 program.

Results: 203 students participated in the study. As a result of the confirmatory factor analysis, the three-factor structure consisting of physical activity, nutrition, and obesity awareness factors were verified, and it was determined that this scale was a valid and reliable scale for the students of pharmacy faculty by evaluating the scale's fit indexes.

Conclusion: The findings obtained in the study revealed that education is effective in increasing the awareness level of obesity for the students of the pharmacy faculty who are the future pharmacists. In this context, it is thought that giving more places for topics such as healthy life, obesity, and weight management in pharmacy faculties will shed light on students' future practices.

Keywords: Confirmatory factor analysis, Obesity, Pharmacy

*Lokman Hekim Dergisi, 2020; 10 (2): 171-178

DOI: $10.31020 /$ mutftd.688839

e-ISSN: $1309-8004$

Geliş Tarihi - Received: 13 Şubat 2020; Kabul Tarihi - Accepted: 22 Mart 2020

iletişim - Correspondence Author: Miray Arslan <eczmirayarslan@gmail.com> 


\section{Giriş}

Obezite, vücuda alınan enerjinin vücutta harcanan enerjiden fazla olması sonucunda harcanamayan enerjinin vücutta yağ olarak depolanması sonucu oluşan bir sağlık sorunudur. ${ }^{1}$ Obezite gelişiminde yaşamın ilk yıllarından başlayarak bireyin beslenme şeklinin önemli rol oynadığı bilinmektedir. Ayrıca, yaş, cinsiyet, çevresel, biyokimyasal, sosyokültürel, psikolojik ve genetik etmenler gibi birçok faktörün obezite oluşumuna yol açtığı görülmektedir., ${ }^{2,3}$ Dünya Sağlık Örgütü (DSÖ) obeziteyi "sağlığı bozacak ölçüde yağ dokularında anormal veya aşırı miktarda yağ birikmesi" olarak tanımlamaktadır. ${ }^{3}$ Obezite tanısının konulmasında sıklıkla beden kitle indeksi (BKi) değerinden yararlanılmaktadır. Bir bireyin kilogram cinsinden ağırlığının, boyunun metrekaresine bölünmesiyle $\left(\mathrm{kg} / \mathrm{m}^{2}\right)$ hesaplanan bu değeri temel alarak DSÖ obeziteyi şu şekilde sınıflamaktadır: ${ }^{4}$

(i) $B K i<18.50 \mathrm{~kg} / \mathrm{m}^{2}$ : zayıf,

(ii) $18.50 \mathrm{~kg} / \mathrm{m}^{2}<$ BKi $<24.99 \mathrm{~kg} / \mathrm{m}^{2}$ : normal,

(iii) $25.00 \mathrm{~kg} / \mathrm{m}^{2}<$ BKi $<29.99 \mathrm{~kg} / \mathrm{m}^{2}$ : fazla kilolu,

(iv) $>=30.00 \mathrm{~kg} / \mathrm{m}^{2}$ : obez.

Tüm dünyada olduğu gibi Türkiye'de de obezite prevelansı giderek artmaktadır. Ülkemizde 1998 yılında yapılan Türkiye Diyabet, Hipertansiyon, Obezite ve Endokrinolojik Hastalıklar Prevalans-I (TURDEP-I) ve 2010 yılında yapılan TURDEP-II çalışmalarına göre, obezite prevalansı \%22.3'ten \%31.2'ye yükselmiştir. ${ }^{5}$ Günümüzde pek çok kronik hastalığın risk faktörleri arasında obezitenin yer aldığı bilinmektedir. Bu bağlamda, obezite prevalansındaki artışa paralel olarak diyabet, hipertansiyon gibi kronik hastalıkların prevanslarında da artış olacağı beklenilmektedir. ${ }^{6}$

Bayraktar (2010), obezitenin nedenleri ve sağlık riskleri hakkında danışmanlık hizmeti sunularak, kişilerin sağlıklı yaşam konusunda bilinçlenmesi ve motivasyonlarının artırııası sağlanabileceğini ifade

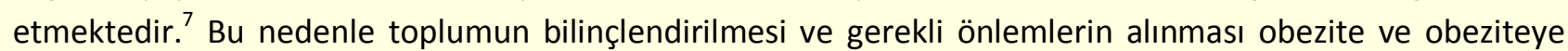
bağlı sağlık sorunlarının önlenmesi açısından oldukça önem arz etmektedir. En yakın ve en kolay ulaşılabilen sağlık danışmanları olarak kabul edilmekte olan eczacılara bu noktada büyük sorumluluklar düşmektedir. Hasta danışmanlığı kapsamında sağlıklı beslenme alışkanlıkları, düzenli ve dengeli beslenme ile egzersizin öneminin vurgulaması gibi konular eczacıların rol alabileceği alanlar arasındadır. Bu bağlamda, birer eczacı adayı olan eczacılık fakültesi öğrencilerinde obeziteye yönelik farkındalık oluşturabilmek oldukça önem arz etmektedir.

Literatürde yer alan çalışmalar incelendiğinde, obeziteye yönelik farkındalık, tutum ve inançların ele alındığı pek çok çalışma ${ }^{8-11}$ olduğu görülmektedir. Buna karşın eczacıların ya da eczacılık fakültesi öğrencilerinin obeziteye yönelik farkındalıklarını inceleyen çalışma sayısı oldukça kısıtlı olup, çalışmalarda genel olarak eczacıların kilo ve obezite yönetimindeki rollerinin ele alındığı tespit edilmiştir. ${ }^{12-14}$ Literatürde yer alan pek çok çalışmada farkındalık, inanç gibi unsurların bireylerin tutumlarının oluşmasında ve oluşan bu tutumların ise davranışların şekillenmesinde etkili olduğu ortaya konulmuştur. ${ }^{15-17} \mathrm{Bu}$ bağlamda, geleceğin eczacılarının obeziteye yönelik sunacağı hizmetlerin geliştirilmesi açısından obeziteye yönelik farkındalık sahibi olmalarının gerekli olduğu düşünülmektedir. Bu bilgi ışığında, çalışmanın temel amacını eczacılık fakültesi öğrencilerinin obeziteye yönelik farkındalıklarının belirlenmesi oluşturmaktadır.

\section{Gereç ve Yöntem}

Bu çalışma kapsamında Ankara Üniversitesi Eczacılık Fakültesi 1. ve 4. sınıfında okumakta olan öğrencilere 2018-2019 eğitim-öğretim yılı bahar döneminde yüz-yüze anket uygulaması yapıımıştır $(N=375)$. Bu çalışmanın örneklem büyüklüğü, örneklem istatistiklerinin normal dağıldığı varsayımı altında kabul edilebilir hata seviyesi yöntemiyle hesaplanmıştır. 0.05 güven düzeyi, $z=1.96, d$ (duyarlılık) $=0.05$ ve $p$ ve $q$ değerlerin 0.50 olarak alınmasıyla ulaşılması gereken minimum örneklem büyüklüğü 190 olarak hesaplanmıştır. Ankara Üniversitesi Etik Kurulunun 06.05.2019 tarihli toplantısında alınan 176 sayılı karar sonrasında anketin 
uygulanmasına başlanılmıştır. Elde edilen verilerin güvenilirliğini arttırmak için ulaşılabilecek maksimum sayıdaki öğrenciye anketin uygulanması hedeflenmiş olup, ankete 274 öğrencinin katılımı sağlanmıştır. Çalışmada, Allen (2011) tarafından geliştirilmiş ve Kafkas ve Özen (2014) tarafından Türkçe geçerlilik ve güvenilirliği yapılmış olan "Obezite Farkındalık Ölçeği” uygulanmıştır. ${ }^{17,18}$ Ölçekte bireylerin obezite farkındalığı, beslenme alışkanlıkları ve fiziksel aktiviteler hakkındaki görüşlerini belirlemek üzere (1) Kesinlikle katılmıyorum, (2) katılmıyorum, (3) katılıyorum, (4) Kesinlikle katılıyorum olacak şekilde 4'lü Likert tipi derecelendirilmeyle hazırlanmış 20 soru yer almaktadır. Anket formunda ayrıca demografik özellikleri belirleyici 5 soru bulunmaktadır.

Anket formundan elde edilen veriler IBM SPSS 22.0 paket programının yardımıyla öncelikle betimleyici istatistiksel analizlere tabi tutulmuş ve ardından LISREL 8.80 programı aracılığı ile doğrulayıcı faktör analizi uygulanmıştır.

\section{Bulgular}

Çalışmaya katılan öğrencilerin $221^{\prime} i$ kadın, $53^{\prime}$ ü ise erkektir. Öğrencilerin $143^{\prime} u ̈ 1 . \operatorname{sınıf,~} 131^{\prime} i$ ise $4 . \operatorname{sınıf}$ öğrencisidir. Çalışma kapsamında öğrencilerin kendi beslenme tarzları hakkında ne düşündükleri de sorulmuş olup, öğrencilerin \%51.5'i sağlıklı bir beslenme tarzına sahip olduğunu ifade etmiştir. Ayrıca 202 öğrencinin kendi BKi değerlerini bildiği ve \%97.4'ünün eczacıların obezitede konusunda toplumun bilinçlendirilmesinde rolü olduğunu düşündüğü ortaya konulmuştur.

Anket çalışmasının temelini oluşturan Obezite Farkındalık Ölçeği'nin değerlendirilmesinde ise doğrulayıcı faktör analizinden (DFA) yararlanılmıştır. Allen (2011) ile Kafkas ve Özen (2014) tarafından yapılan çalışmalarda ${ }^{18,19}$ elde edilen fiziksel aktivite (FA), beslenme (B) ve obezite farkındalık (OF) faktörlerinin çalışma örneklemi için de uygun olup olmadığını değerlendirebilmek amacıyla yapılan DFA sonucunda üçfaktörlü yapı doğrulanmış olup, analiz sonuçları Tablo 1'de sunulmuştur.

Tablo 1'deki ortalama değerlerine bakıldığında öğrencilerin yanıt ortalamalarının genel olarak 3'ün üzerinde olduğu görülmektedir. En yüksek yanıt ortalamasına sahip olan ifade "Obez bireylerin kilolarıyla ilişkili, örneğin diyabet gibi sağlık sorunlarının gelişmesinde daha yüksek risk vardır." ve en düşük yanıt ortalamasına sahip ifade ise "Kısa mesafe (10 dakika) yürüyüş veya kısa aktiviteler yapmak kötü sağlık etkilerini önlemek ve sağlıklı olmak için yeterlidir." olarak belirlenmiştir.

Tablo 1 ve Şekil 1'deki diyagramda verilmiş olan standardize edilmiş parametre yük değerlerine bakıldığında OF faktörünü en fazla etkileyen unsurun 0.71 'lik bir yükle “Obez bireylerin arkadaşlık ve özgüven problemleri daha fazla olabilir." ifadesi olduğu ve B faktörünü en fazla etkileyen unsurun ise 0.61'lik bir yükle, "Her gün abur cubur yemek gibi kötü yeme davranışları önemli bir obezite olma nedenidir." ifadesi olduğu görülmektedir. "Düzenli egzersiz; stresten kurtulma ve rahatlama sağlayabilir." ifadesinin ise 0.62 'lik bir yükle FA faktörünü en fazla etkileyen ifade olduğu tespit edilmiştir. DFA sonucuna elde edilen yol (path) diyagramı Şekil 1'de verilmiştir. 
Tablo 1. Faktörler, ifadeler ve ifadelere verilen yanıt ortalamaları, standardize yük değerleri ve $\mathrm{R}^{2}$ değerleri

\begin{tabular}{|c|c|c|c|}
\hline Faktör / ífadeler & Ortalama & $\begin{array}{l}\text { Standardize } \\
\text { edilmiş } \\
\text { yükler }\end{array}$ & $\mathbf{R}^{2}$ \\
\hline \multicolumn{4}{|l|}{ Obezite Farkındalık (OF) } \\
\hline s1 Normal bir kiloda olmak sağlıklı bir kişi olmak için önemlidir. & 3.562 & 0.37 & 0.13 \\
\hline $\begin{array}{l}\text { s2 Obez bireylerin kilolarıyla ilişkili, örneğin diyabet gibi sağlık sorunlarının } \\
\text { gelişmesinde daha yüksek risk vardır. }\end{array}$ & 3.693 & 0.54 & 0.29 \\
\hline s3 Obezite okulumda, toplumda ve ülkemde artıyor & 3.515 & 0.48 & 0.23 \\
\hline $\begin{array}{l}\text { s4 Dışarıda aktif hareket gerektiren aktivitelere katılmak yerine bilgisayar oyunları } \\
\text { oynamak, TV izlemek veya bilgisayarda zaman harcamak önemli bir obezite olma } \\
\text { nedenidir. }\end{array}$ & 3.449 & 0.67 & 0.45 \\
\hline s5 Obez bireylerin arkadaşlık ve özgüven problemleri daha fazla olabilir. & 3.270 & 0.71 & 0.51 \\
\hline s6 Ailemizdeki diğer insanlar obezse sizin obez olma ihtimaliniz daha yüksektir. & 2.789 & 0.36 & 0.13 \\
\hline $\begin{array}{l}\text { s8 Akran baskısı (akran faaliyetleri, beslenme alışkanlıkları vb.) obezite } \\
\text { nedenlerinde önemli rol oynar. }\end{array}$ & 3.156 & 0.51 & 0.26 \\
\hline s9 Dergiler, filmler ve TV yorumları obeziteye neden olmada önemli rol oynar. & 2.635 & 0.50 & 0.25 \\
\hline s20 32 BKi değeri, sağıklı bir BKi değeridir.* & 3.606 & 0.25 & 0.06 \\
\hline \multicolumn{4}{|l|}{ Beslenme (B) } \\
\hline s11 Sağlıklı olmak için her sabah kahvaltıda besleyici gıdalar yemek önemlidir. & 3.478 & 0.53 & 0.28 \\
\hline s12 Eğer düzenli olarak fiziksel aktivite yapmazsam kendimi huzursuz hissederim. & 2.799 & 0.46 & 0.21 \\
\hline $\begin{array}{l}\text { s13 Her gün abur cubur yemek gibi kötü yeme davranışları önemli bir obezite olma } \\
\text { nedenidir. }\end{array}$ & 3.507 & 0.61 & 0.38 \\
\hline s14 Sağlıklı olmak için çoğu akşam ailelerle birlikte yemek önemlidir. & 2.865 & 0.28 & 0.08 \\
\hline s15 Sağlıklı olmak için her gün 8 bardak su içmek önemlidir. & 3.270 & 0.35 & 0.12 \\
\hline \multicolumn{4}{|l|}{ Fiziksel Aktivite (FA) } \\
\hline s16 Düzenli egzersiz; stresten kurtulma ve rahatlama sağlayabilir. & 3.442 & 0.62 & 0.30 \\
\hline $\begin{array}{l}\text { s17 Kısa mesafe (10 dakika) yürüyüş veya kısa aktiviteler yapmak kötü sağlık } \\
\text { etkilerini önlemek ve sağlıklı olmak için yeterlidir. }\end{array}$ & 2.526 & 0.16 & 0.03 \\
\hline s18 Egzersiz boyunca kalori yakmak sağlıklı vücut ağırlığını korumak için gereklidir. & 2.978 & 0.51 & 0.26 \\
\hline $\begin{array}{l}\text { s19 Haftada } 3 \text { gün } 30-60 \text { dakika orta şiddette egzersiz yapmak sağıklı vücut } \\
\text { ağırlığını korumak için yeterlidir. }\end{array}$ & 3.018 & 0.40 & 0.16 \\
\hline
\end{tabular}

*olumsuz yapıda hazırlanmış bu ifada analiz sırasında ters çevrilmiştir. 


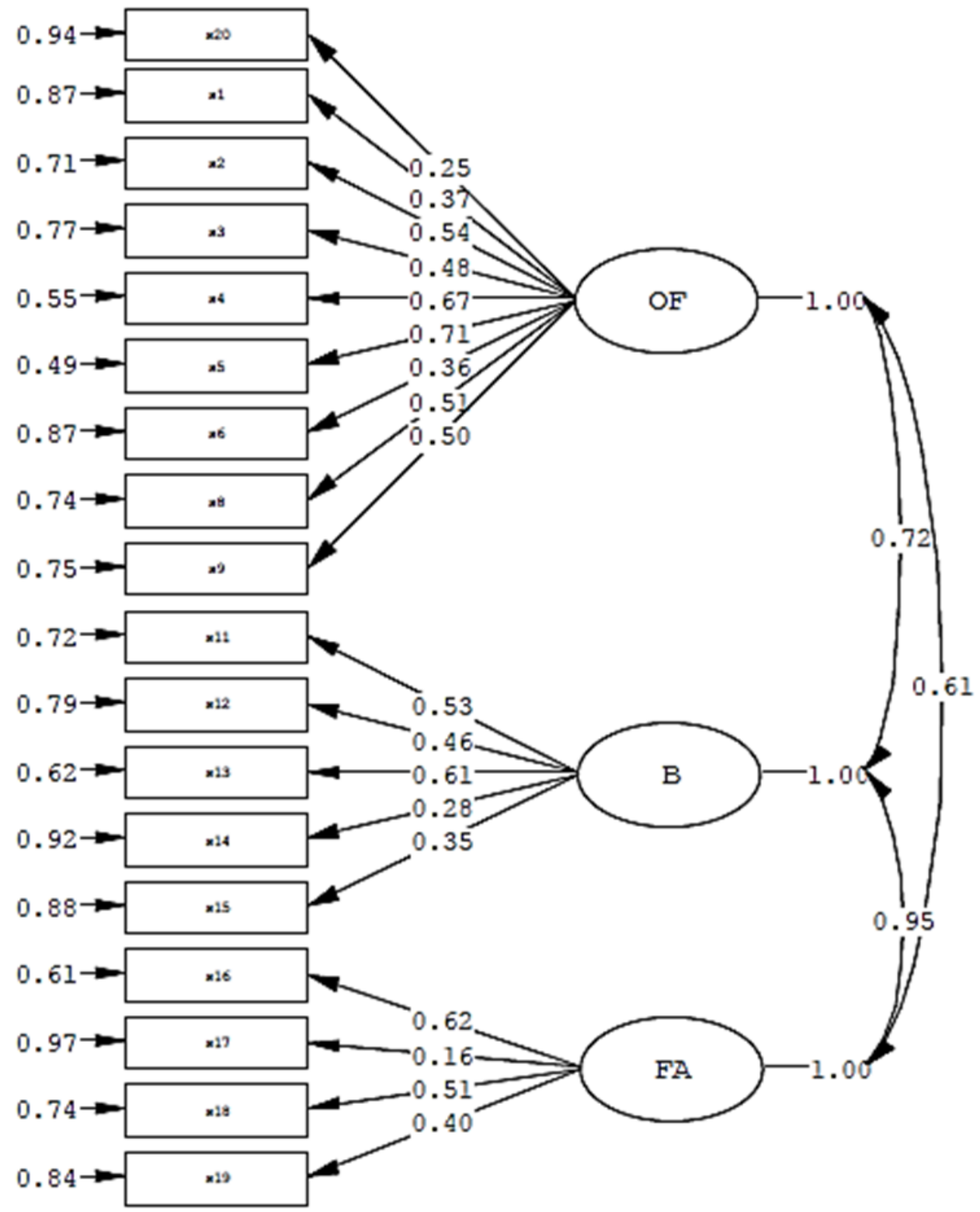

Şekil 1. DFA path diyagramı

DFA modelinin uyum iyiliğini test edilebilmek için en sık ki-kare $\left(\chi^{2}\right)$, uyum iyiliği indeksi (GFI), düzeltiliş uyum iyiliği indeksi (AGFI), hata kareleri ortalamalarının karekökü (RMR), standartlaştırılmış RMR (SRMR) ve yaklaşık hataların ortalama karekökü (RMSEA) değerleri kullanılmaktadır. ${ }^{20}$ Analiz sonucunda elde edilen DFA modeline ait uyum indeksi değerleri ile bu indekslerin kabul düzeyleri Tablo 2 'de verilmiştir.

Tablo 2. DFA modeli için uyum indeksleri

\begin{tabular}{llll}
\hline Uyum indeksi & İyi Uyum Düzeyi & Kabul Edilebilir Uyum Düzeyi & Alınan Değer \\
\hline$\chi 2 /$ d.f. & $0 \leq{ }^{2} /$ d.f. $<2$ & $2 \leq \chi^{2} /$ d.f. $\leq 3$ & 2.833 \\
RMSEA & $0 \leq$ RMSEA $<0.05$ & $0.05 \leq R M S E A \leq 0.10$ & 0.082 \\
RMR & $0 \leq R M R \leq 0.05$ & $0.05<R M R \leq 0.10$ & 0.038 \\
SRMR & $0 \leq$ SRMR $\leq 0.05$ & $0.05<$ SRMR $\leq 0.10$ & 0.073 \\
GFI & $0.95 \leq$ GFI $\leq 1$ & $0.90 \leq$ GFI $\leq 0.95$ & 0.090 \\
AGFI & $0.90 \leq \mathrm{AGFI} \leq 1$ & $0.85 \leq \mathrm{AGFI} \leq 0.90$ & 0.087 \\
\hline
\end{tabular}

Tablo 2'de verilen uyum ölçütleri değerleri ele alındığında, DFA modelinin kabul edilebilir bir uyum gösterdiğini söylemek mümkündür. 
Çalışmada ek olarak demografik özellikler ile sağlıklı beslenme, BKi değerini bilme ve eczacıların obezitede sorumlu olup olmadığı görüşlerinin faktör skorları üzerinde etkisi olup olmadığının belirlenmesi için $t$ testinden yararlanılmıştır. Tablo 3 'te $t$-testi sonuçları sunulmuştur.

Tablo 3. t-testi sonuçları

\begin{tabular}{lllllllllll}
\hline & Cinsiyet & \multicolumn{3}{c}{ Sınıf } & \multicolumn{3}{c}{ Sağlıklı Beslenme } & \multicolumn{2}{c}{ BKi } & \multicolumn{3}{c}{ Eczacı Sorumluluğu } \\
Faktörler & $\boldsymbol{t}$ & Sig. & $\boldsymbol{t}$ & Sig. & $\boldsymbol{t}$ & Sig. & $\boldsymbol{t}$ & Sig. & $\boldsymbol{t}$ & \multicolumn{1}{c}{ Sig. } \\
\hline OF & -0.398 & 0.691 & -2.122 & $0.035^{*}$ & 2.718 & $0.007^{*}$ & 2.132 & $0.034^{*}$ & 0.064 & 0.949 \\
B & 0.101 & 0.920 & -2.077 & $0.039^{*}$ & 4.899 & $0.000^{*}$ & 1.481 & 0.140 & $-0,301$ & 0,763 \\
FA & -0.735 & 0.463 & -0.491 & 0.623 & 2.801 & $0.005^{*}$ & 0.979 & 0.329 & $-0,806$ & 0,421 \\
\hline
\end{tabular}

Tablo $3^{\prime}$ te verilen bilgiler incelendiğinde, cinsiyetin ve eczacıların obezitede sorumlu olup olmadığı görüşünün \%5 anlam düzeyinde faktör skorları üzerinde istatistiksel olarak anlamlı bir farklılık oluşturmadığı görülmektedir.

Öğrencilerin sınıflarının faktör skorları üzerindeki etkisini görmek üzere yapılan $t$-testi sonucunda obezite farkındalık ve beslenme faktörlerinde \%5 anlam düzeyinde grupların ortalamaları arasında istatistiksel olarak anlamlı bir farklııık oluşturduğu ve bu farklılığın 4. sınıflara ait ortalamanın 1. sınıflardan daha yüksek oluşundan kaynaklandığı tespit edilmiştir.

Yapılan $t$-testi ile \%5 anlam düzeyinde öğrencilerin sağlıklı beslenip beslenmedikleri düşüncesinin tüm faktör skorları üzerinde istatistiksel olarak anlamlı farklılık oluşturduğu ve sağlıklı beslendiğini düşünenlerin ortalamalarının daha yüksek olduğu ortaya konulmuştur.

Son olarak, BKi değerini bilen ve bilmeyen öğrencilerin faktör skorları üzerindeki etkisini görebilmek için yapılan $t$-testi sonucunda $\% 5$ anlam düzeyinde sadece obezite farkındalık faktöründe ortalamalar arasında istatistiksel olarak anlamlı bir farklılık olduğu belirlenmiştir. Obezite farkındalık faktöründe BKi değerini bilen öğrencilerin ortalamasının daha yüksek olduğu görülmüştür.

\section{Tartışma}

Bu çalışma sonucunda, ankette kullanılan Obezite Farkındalık Ölçeği'nin eczacılık fakültesi öğrencileri için de Allen (2011) ve Kafkas ve Özen (2014) tarafından yapılan çalışmalar ile paralel şekilde üç faktörlü bir yapı oluşturduğu tespit edilmiştir. ${ }^{18,19}$ Kafkas ve Özen (2014)'in çalışmasında olduğu gibi faktörlerde yer alan bazı maddelerin farklı faktörler altında yer aldığı görülmüştür. ${ }^{19}$ Doğrulayıcı faktör analizi bulguları ışığında bu ölçeğin eczacılık fakültesi öğrencilerinin obezite farkındalıklarının belirlenmesinde geçerli ve güvenilir bir ölçme aracı olarak kullanılabileceğini söylemek mümkündür.

Anket sonuçlarına göre en yüksek yanıt ortalamasına sahip olan "Obez bireylerin kilolarıyla ilişkili, örneğin diyabet gibi sağlık sorunlarının gelişmesinde daha yüksek risk vardır." ifadesi öğrencilerin obezitenin önemli sağlık sorunlarının risk faktörleri arasında yer aldığı konusundaki farkındalı̆̆ını ortaya koymaktadır. Obezite farkındalık faktöründe en düşük yanıt ortalaması "Dergiler, filmler ve TV yorumları obeziteye neden olmada önemli rol oynar." ifadesine aittir.

Anket sonuçlarına göre eczacılık fakültesi 1. ve 4. sınıf öğrencilerinin genel olarak "Kısa mesafe (10 dakika) yürüyüş veya kısa aktiviteler yapmak kötü sağlık etkilerini önlemek ve sağlıklı olmak için yeterlidir" ve "Dışarıda aktif hareket gerektiren aktivitelere katılmak yerine bilgisayar oyunları oynamak, TV izlemek veya bilgisayarda zaman harcamak önemli bir obezite olma nedenidir" ifadelerine yüksek yanıt verdiği görülmektedir. Bu durum çalışmaya katılan öğrencilerin aktif bir yaşamanın obeziteyi önleme de etkili olduğu bilincine sahip olduğunun bir göstergesidir. Türkiye Beslenme ve Sağlık Araştırması 2010 raporunda "Sağ|ıklı Beslenelim, Kalbimizi Koruyalım" çalışmasına yer verilmiş olup, bu çalışmadaki katııımcıların sadece \%3.5'inin düzenli fiziksel aktivite yaptıkları beyan edilmiştir. ${ }^{21}$ Sağlık Bakanlığı tarafından 2003 yılında yapılan Ulusal Hane Halkı Araştırmasına göre ise katılımcıların \%20.32'sinin hareketsiz yaşadığı, \%15.99'unun yetersiz düzeyde fiziksel aktivite yaptığı saptanmıştır. ${ }^{23}$ Bu bağlamda, eczacı adaylarının bu 
konunun bilincinde olması mesleki uygulamalarında hastalarda bu konuda farkındalık oluşturulmasında ve öneriler sunulmasında önem arz etmektedir.

Sözen ve Bebek (2018) obeziteye yönelik farkındalığı ele aldıkları çalışmada kadınların farkındalık düzeyinin daha yüksek olduğunu ortaya koymuşlardır. ${ }^{23}$ Bu çalışmada ise cinsiyetin ölçekte yer alan faktörlerde bir farklıık oluşturmadığı tespit edilmiştir.

Obezite tedavisinde hastaya sunulan danışmanlık hizmetlerinin multidisipliner yapıda olduğu ve verimli bir şekilde yönetilmesi ile belirgin kilo kayıpları sağlandığı ortaya konulmuştur. ${ }^{24}$ Bu bağlamda eczacıların hastanın yaşam tarzı değişikliklerini sürdürmesine destek olma, ilaç tedavisine olan uyuncunu arttırma, kilo verilmesine yönelik ürünler hakkında danışmanlık hizmeti sunmanın yanı sıra kan basıncı, lipid düzeyleri ve metabolik/endokrin bulgular hakkında hastaları bilgilendirmesiyle gerek obezitenin gerekse obeziteye bağlı olası komplikasyonların önlenmesine katkı sağlanacaktır. ${ }^{7}$ Çalışma bulgularına bakıldığında da paralel şekilde öğrencilerin \%97.4'ünün eczacıların obezitede konusunda toplumun bilinçlendirilmesinde rolü olduğunu düşündükleri görülmektedir.

Bireylerin sergiledikleri davranışların temelinde bu davranışlarla ilişkili tutum, bilgi, inanç ve farkındalık gibi öncüllerin etkili olduğu bilinmektedir. Dastani ve ark. (2004), serbest eczacıların dünya genelinde bir salgın olarak görülmekte olan obeziteye yönelik farkındalığın artmasıyla bu konudaki danışmanlıklarının da gelişeceğini belirtmiştir. ${ }^{12} \mathrm{Bu}$ nedenle eczacılık fakültesi öğrencilerinin obezite ve kilo yönetimi gibi konularda hastalara sunacakları hizmet kalitesinin arttırılmasında eğitim öğretim hayatlarında obeziteye yönelik kazandıkları farkındalığın önemli olduğu düşünülmektedir. Sözen ve Bebek (2018), öğrencilerin öğretim gördüğü sınıf düzeyleri arttıkça obezite farkındalık düzeylerinin de arttığını tespit etmiştir. Bu çalışmada elde edilen sonuç da buna paraleldir. ${ }^{23}$ Eczacılık fakülteleri özelinde bu durumu ele aldığımızda, öğrencilerin her geçen yıl sağlık ile ilgili bilgi birikimlerinin artışı, obezitenin pek çok hastalığın tetikleyicisi olduğu konusunda bilgi edinmelerini de sağlamaktadır. Bu bağlamda, sınıf düzeyinin artışının farkındalığı arttırmasının beklenen bir durum olduğunu söylemek mümkündür.

Sonuç olarak, eczacılık fakültesi müfredatında sağlıklı yaşam, obezite ve kilo yönetimi konularına yer verilmesi, bu konuları ele alan seçmeli derslerin müfredata alınması gibi eğitsel faaliyetler öğrencilerin mesleki hayatlarındaki uygulamalarına ışık tutacaktır. Ayrıca, eczacılık fakültelerinde obezite ile ilgili konferans ve seminer gibi bilimsel faaliyetlerin düzenlenmesi, bu konu ile ilgili broşür, afiş benzeri materyallerin hazırlanması, sağlıklı yaşam için öğrencilerin katııım sağlayacağı aktivitelerin organize edilmesi ile öğrencilerin farkındalık düzeylerinin geliştirilebileceği düşünülmektedir.

\section{Bilgi}

Yazarlar arasında çıkar çatışması bulunmamaktadır.

\section{Kaynaklar}

1. Altunkaynak B, Özbek E. Obezite: Nedenleri ve Tedavi Seçenekleri. Van Tıp Dergisi 2006;13(4):138-142.

2. Tam A, Çakır B. Birinci basamakta obeziteye yaklaşım. Ankara Medical Journal 2012;12(1): 37-41.

3. Evren B. Obezite. İçinde: Aktay G, Yakıncı E. Editors. Eczacının Başucu Rehberi, TEB Eczacılık Akademisi Yayını, Ankara, 2. Baskı, 2012; s:245-252.

4. WHO. Obesity and Overweight [Fact Sheet; updated February 2018] http://www.who.int/news-room/factsheets/detail/obesity-and-overweight. 2017. (Erişim:25.03.2018)

5. Satman i. Türkiye'de obezite sorunu. Turkiye Klinikleri Gastroenterohepatology-Special Topics 2016;9(2):1-11.

6. Kalan I, Yeşil Y. Obezite ile Illişkili Kronik Hastalıklar, MiSED 2010;23-24:79.

7. Bayraktar A. Obezite Tedavisinde Eczacının Rolü ve Katkısı, MiSED 2010;23-24:106.

8. Hankey $\mathrm{CR}$, et al. Eating habits, beliefs, attitudes and knowledge among health professional regarding the links between obesity, nutrition and health. Public Health Nutrition 2014;7(2):337-343.

9. Budd GM, et al. Health care professionals' attitudes about obesity: an integrative review. Applied Nursing Research 2011;24(3):127-137.

10. Kahraman, $G$, Baş $T$, Akbolat $M$. Obeziteye yönelik tutum ve inançların geliş̧irilmesinde sağık programlarının etkisi. Acıbadem Üniversitesi Sağlık Bilimleri Dergisi 2015;6(2):89-98. 
11. Usta E, Acar K, Aygin D. Sağlık Hizmetleri Meslek Yüksekokulu Öğrencilerinin Obeziteye İlişkin Tutumları. Electronic Journal of Vocational Colleges 2015;46-53.

12. Dastani HB, Brown CM, O'Donnell DC. Combating the obesity epidemic: community pharmacists counseling on obesity management. Annals of Pharmacotherapy 2004;38(11): 1800-1804.

13. Um ISI, et al. Managing obesity in pharmacy: the Australian experience. Pharm World Sci 2010;32:(711-720). https://doi.org/10.1007/s11096-010-9426-5

14. George K, et al. Community pharmacy contribution to weight management: identifying opportunities. International journal of pharmacy practice 2010;18(1):7-12.

15. Ajzen I. From intentions to actions: A theory of planned behavior. In Kuhl J. And Beckman J. editors. Action control: From cognition to behavior. Springer, Heidelberg. 1985; pp.11-39.

16. Tarhan N, Arslan M, Şar S. A structural equation model for pharmacy students' acquiring knowledge-based behavior towards complementary and alternative medicine. EUJIM 2017;( 16):54-60. https://doi.org/10.1016/j.eujim.2017.10.007.

17. Arslan M, Tarhan N, Şar S. Examination of the community pharmacists' intention to pharmacist partnership using the Theory of Planned Behavior: a structural equation model. IJPER 2017;(51):216-225. https://doi.org/10.5530/ijper.51.2.27

18. Allen A. Effects of educationalıntervention on children's knowledge of obesity risk factors. Ph.D. Thesis, Carroll College, 2011.

19. Kafkas M, Gökmen ÖZN. Obezite Farkındalık Ölçeği'nin (OfÖ) Türkçeye Uyarlanması: Bir Geçerlik Ve Güvenirlik Çalışması. İnönü Üniversitesi Beden Eğitimi ve Spor Bilimleri Dergisi 2014;1(2):1-15.

20. Raykov T, Marcoulides GA. On multilevel model reliability estimation from the perspective of structural equation modeling. Structural Equation Modeling 2006;13(1):130-141.

21. Sağlık Bakanlığı Sağlık Araştırmaları Genel Müdürlüğü. "Türkiye Beslenme ve Sağlık Araştırması 2010: Beslenme durumu ve alışkanlıklarının değerlendirilmesi sonuç raporu." Sağlık Bakanlığı Yayın 931 (2014).

22. Sağlık Bakanlığı. Türkiye Ulusal Hanehalkı Sağlık Harcamaları Araştırması 2002-2003. Ankara: Sağlık Bakanlığı Yayınları, 2006.

23. Sözen H, Bebek G. Üniversite Öğrencilerinin Obezite Farkındalığımım Belirlenmesi, ICPESS 2018;4.

24. Feigenbaum A, et al. Influence of intense multidisciplinary follow-up and orlistat on weight reduction in a primary care setting. BMC Fam Pract 2005; 6(Article number 5). 